\title{
Fuzzy Controller Based 3Phase 4Wire Shunt Active Filter for Mitigation of Current Harmonics with Combined p-q and $\mathbf{I}_{\mathbf{d}}-\mathbf{I}_{\mathbf{q}}$ Control Strategies
}

\author{
Mikkili Suresh, Anup Kumar Panda, Y. Suresh \\ Department of Electrical Engineering, National Institute of Technology, Rourkela, India \\ E-mail:msuresh.ee@gmail.com,akpanda.ee@gmail.com,ysuresh.ee@gmail.com \\ Received November 14, 2010; revised December 15, 2010; accepted December 16, 2010
}

\begin{abstract}
As more and more variable frequency drives (VFDs), electronic ballasts, battery chargers, and static Var compensators are installed in facilities, the problems related to harmonics are expected to get worse. As a result Active power filter (APF) gains much more attention due to excellent harmonic compensation. But still the performance of the active filter seems to be in contradictions with different control strategies. This paper presents detailed analysis to compare and elevate the performance of two control strategies for extracting reference currents of shunt active filters under balanced, un-balanced and non-sinusoidal conditions by using Fuzzy controller. The well known methods, instantaneous real active and reactive power method $(p-q)$ and active and reactive current method $\left(i_{d}-i_{q}\right)$ are two control methods which are extensively used in active filters. Extensive Simulations are carried out with fuzzy controller for both $p-q$ and $I_{d}-I_{q}$ methods for different voltage conditions and adequate results were presented. Simulation results validate the superior performance of active and reactive current control strategy $\left(i_{d}-i_{q}\right)$ with fuzzy controller over active and reactive power control strategy $(p-q)$ with fuzzy controller.
\end{abstract}

Keywords: Harmonic Compensation, Shunt Active Power Filter, p-q Control Strategy, $\mathrm{i}_{\mathrm{d}}-\mathrm{i}_{\mathrm{q}}$ Control Strategy, Fuzzy Controller

\section{Introduction}

Highly automatic electric equipments, in particular, cause enormous economic loss every year. Owing both power suppliers and power consumers are concerned about the power quality problems and compensation techniques. In recent years, single-phase electronic equipments have been widely used in domestic, educational and commercial appliances. These equipments include computers, communication equipments, electronic lighting ballasts etc. Also, a large number of computers are turned on at the same time. Each computer and its related devices have a diode rectifier to convert AC electricity to DC one. In other words, those equipments draw non- sinusoidal currents which pollute the utility line due to the current harmonics generated by the nonlinear loads [1]. It is noted that non-sinusoidal current results in many problems for the utility power supply company, such as: low power factor, low energy efficiency, electromagnetic interference (EMI), distortion of line voltage etc. and it is noted that, in three-phase four-wire system, zero line may be overheated or causes fire disaster as a result of excessive harmonic current going through the zero line three times or times that of three. Thus a perfect compensator is necessary to avoid the consequences due to harmonics [2]. Though several control strategies have been developed but still two control theories, instantaneous active and reactive currents $\left(i_{d}-i_{q}\right)$ method and instantaneous active and reactive power $(p-q)$ methods are always dominant. Present paper mainly focused on two control strategies ( $\mathrm{p}-\mathrm{q}$ and $\mathrm{I}_{\mathrm{d}}-\mathrm{I}_{\mathrm{q}}$ ) with fuzzy controller [3]. To validate current observations, Extensive Simulations are carried out with fuzzy controller for both $\mathrm{p}-\mathrm{q}$ and $\mathrm{I}_{\mathrm{d}}-\mathrm{I}_{\mathrm{q}}$ methods for different voltage conditions like sinusoidal, non-sinusoidal, and un-balanced conditions and adequate results were presented. On observing the performance of $i_{d}-i_{q}$ control strategy with fuzzy controller is quite good over p-q control strategy with fuzzy controller. 


\section{Control Strategy}

In this section two control strategies are discussed in detail. Ideal analysis has done in steady state conditions of the active power filter. Steady state analysis using Fast Fourier Transform (FFT) for the two control methods that are presented are now briefly enlightened.

\subsection{Instantaneous Real and Reactive Power Method (p-q)}

The active filter currents are achieved from the instantaneous active and reactive powers $p$ and $q$ of the non-linear load. Figure 1 shows the block diagram to attain reference currents from load. Transformation of the phase voltages $v_{a}, v_{b}$, and $v_{c}$ and the load currents $i_{L a}$, $i_{L b}$, and $i_{L c}$ into the $\alpha-\beta$ orthogonal coordinates are given in Equation (1-2). The compensation objectives of active power filters $[4,5]$ are the harmonics present in the input currents. Present architecture represents three phase four wire and it is realized with constant power controls strategy [6]. Figure 2 illustrates control block diagram and Inputs to the system are phase voltages and line currents of the load. It was recognized that resonance at relatively high frequency might appear between the source impedance. So a small high pass filter is incorporated in the system. The power calculation is given in detail form in Equation (3).

$$
\begin{gathered}
{\left[\begin{array}{l}
v_{0} \\
v_{\alpha} \\
v_{\beta}
\end{array}\right]=\sqrt{\frac{2}{3}}\left[\begin{array}{ccc}
\frac{1}{\sqrt{2}} & \frac{1}{\sqrt{2}} & \frac{1}{\sqrt{2}} \\
1 & -\frac{1}{2} & -\frac{1}{2} \\
0 & \frac{\sqrt{3}}{2} & -\frac{\sqrt{3}}{2}
\end{array}\right]\left[\begin{array}{l}
v_{a} \\
v_{b} \\
v_{c}
\end{array}\right]} \\
{\left[\begin{array}{l}
i_{0} \\
i_{\alpha} \\
i_{\beta}
\end{array}\right]=\sqrt{\frac{2}{3}}\left[\begin{array}{ccc}
\frac{1}{\sqrt{2}} & \frac{1}{\sqrt{2}} & \frac{1}{\sqrt{2}} \\
1 & -\frac{1}{2} & -\frac{1}{2} \\
0 & \frac{\sqrt{3}}{2} & -\frac{\sqrt{3}}{2}
\end{array}\right]\left[\begin{array}{l}
i_{L_{a}} \\
i_{L b} \\
i_{L c}
\end{array}\right]} \\
{\left[\begin{array}{l}
p_{0} \\
p \\
q
\end{array}\right]=\left[\begin{array}{ccc}
v_{0} & 0 & 0 \\
0 & v_{\alpha} & v_{\beta} \\
0 & v_{\beta} & -v_{\alpha}
\end{array}\right]\left[\begin{array}{l}
i_{0} \\
i_{\alpha} \\
i_{\beta}
\end{array}\right]}
\end{gathered}
$$

From Figure 2 we can observe a high pass filter with cut off frequency $50 \mathrm{~Hz}$ separates the powers $-\tilde{p}$ from $p$ and a low -

Pass filter separates $\bar{p}_{0}$ from $p_{0}$. The powers current $\tilde{p}$ and $p_{0}$ of the load, together with $q$, should be compensated to provide optimal power flow to the source. It is Important to note that system used is three phase four wire, so additional neutral currents has to be supplied by the shunt active power filter thus $P_{\text {loss }}$ is incorporated to
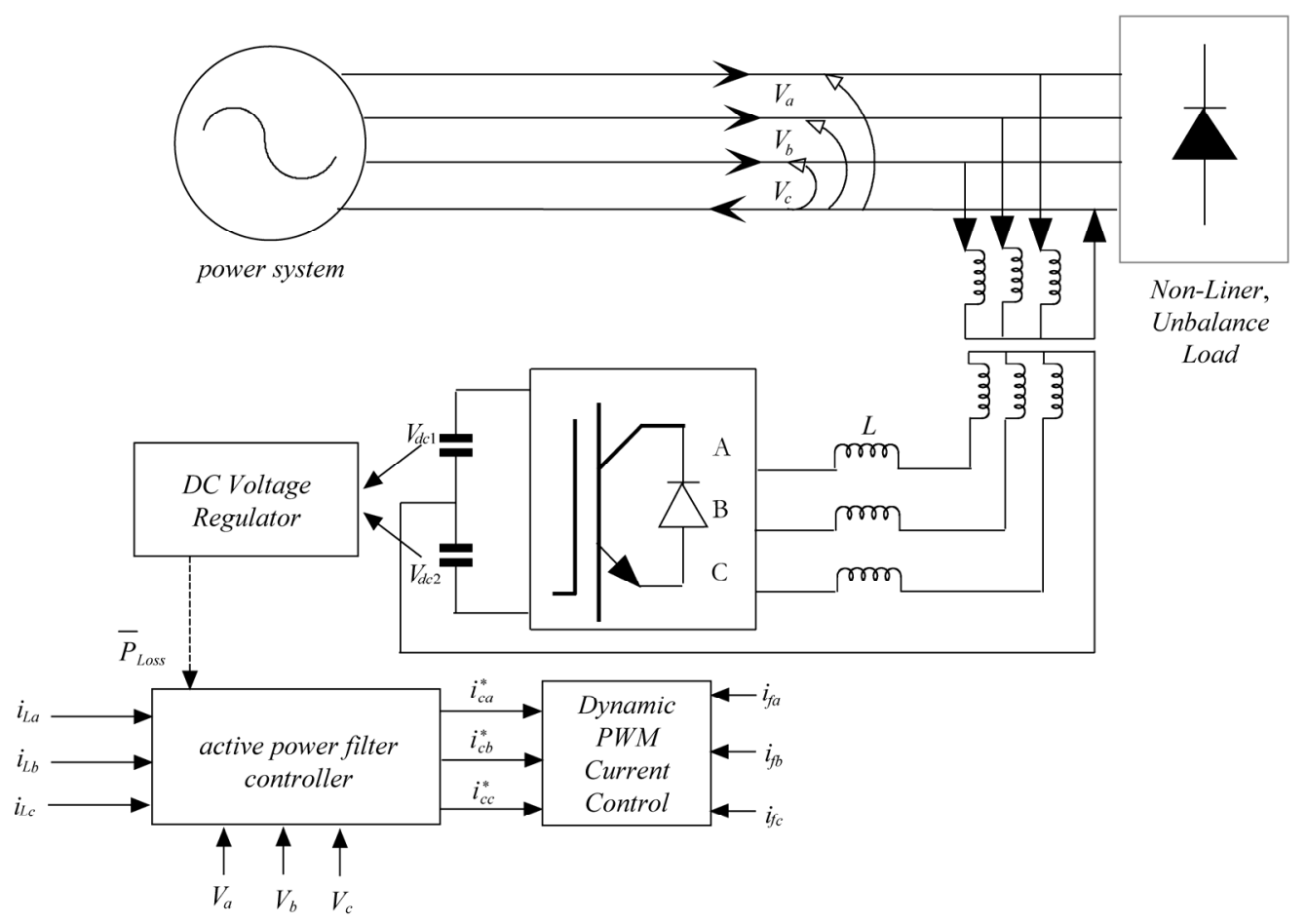

Figure 1. Shows a basic architecture of three-phase - four wire shunt active filter. 


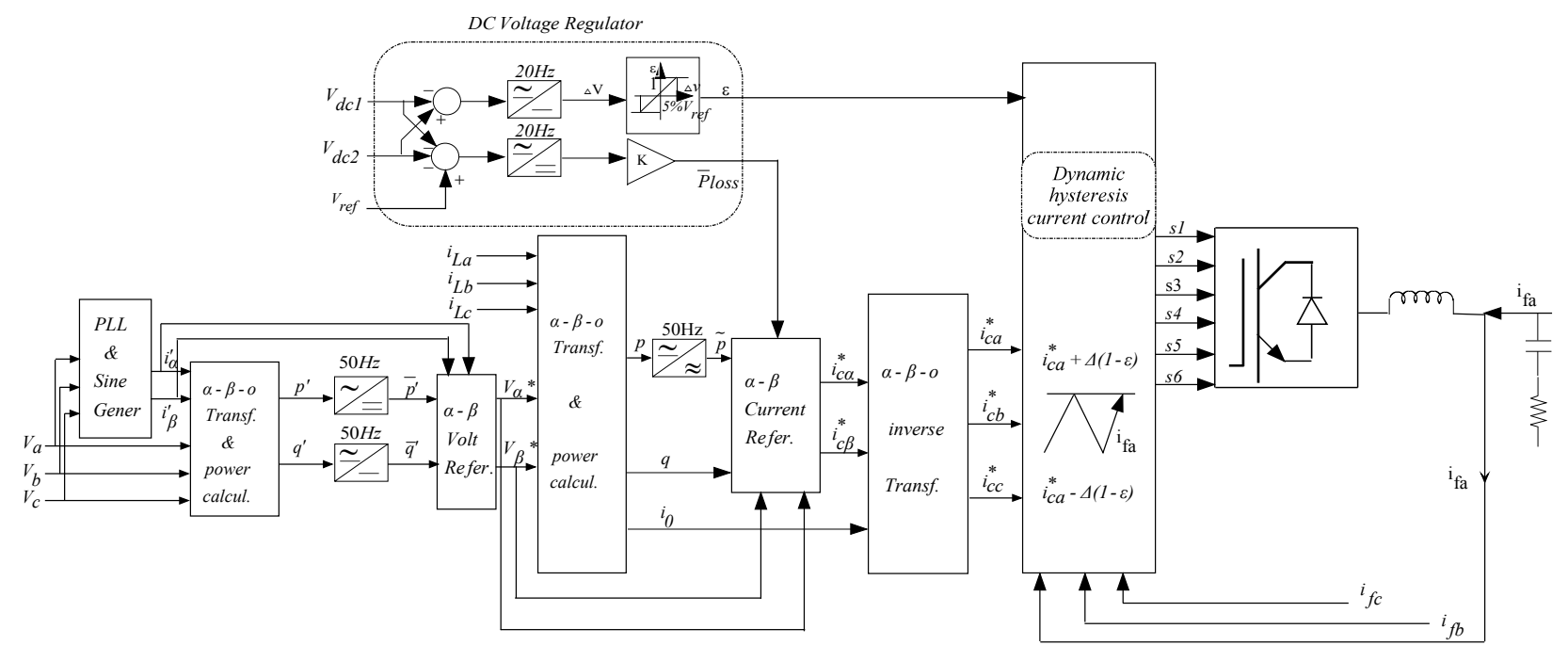

Figure 2. Control block diagram of shunt active power filter.

correct compensation error due to feed forward network unable to suppress the zero sequence power. Since active filter compensates the whole neutral current of the load in the presence of zero-sequence voltages, the shunt active filter eventually supplies $p_{o}$. Consequently if active filter supplies $p_{o}$ to the load, this make changes in $\mathrm{dc}$ voltage regulator, hence additional amount of active power is added automatically to $P_{\text {loss }}$ which mainly provide energy to cover all the losses in the power circuit in the active filter. Thus, with this control strategy shunt active filter gains additional capability to reduce neutral currents and there-by supply necessary compensation when it is most required in the system. Thus the $\alpha \beta$ reference currents can be found with following equation [7].

$$
\begin{gathered}
{\left[\begin{array}{c}
i_{c \alpha} * \\
i_{c \beta} *
\end{array}\right]=\frac{1}{v_{\alpha}^{2}+v_{\beta}^{2}}\left[\begin{array}{cc}
v_{\alpha} & v_{\beta} \\
v_{\beta} & -v_{\alpha}
\end{array}\right]\left[\begin{array}{c}
-\tilde{p}+\Delta \bar{p} \\
-q
\end{array}\right]} \\
\Delta \bar{p}=\bar{p}_{0}+\bar{p}_{\text {Loss }}
\end{gathered}
$$

where $\tilde{p}$ is the ac component / oscillating value of $p$

$\overline{p_{0}}$ is the dc component of $p_{0}$

$P_{\text {loss }}$ is the losses in the active filter

$\frac{P_{\text {loss }}}{P_{\text {loss }}}$ is the average value of $P_{\text {loss }}$

$\Delta p$ Provides energy balance inside the active power filter and using Equation (5) inverse transformation can be done.

$$
\left[\begin{array}{l}
i_{c a} * \\
i_{c b} * \\
i_{c c} *
\end{array}\right]=\sqrt{\frac{2}{3}}\left[\begin{array}{ccc}
\frac{1}{\sqrt{2}} & 1 & 0 \\
\frac{1}{\sqrt{2}} & -\frac{1}{2} & \frac{\sqrt{3}}{2} \\
\frac{1}{\sqrt{2}} & -\frac{1}{2} & -\frac{\sqrt{3}}{2}
\end{array}\right]\left[\begin{array}{c}
-i_{0} \\
i_{c \alpha} * \\
i_{c \beta} *
\end{array}\right]
$$

where $i_{c a}{ }^{*}, i_{c b}{ }^{*}, i_{c c} *$ are the instantaneous three-phase current references

In addition PLL (Phase locked loop) employed in shunt filter tracks automatically, the system frequency and fundamental positive-sequence component of three phase generic input signal [8]. Appropriate design of PLL allows proper operation under distorted and unbalanced voltage conditions. Controller includes small changes in positive sequence detector as harmonic compensation is mainly concentrated on three phase four wire. As we know in three- phase three wire, $v_{a}{ }^{\prime}, v_{b}{ }^{\prime}, v_{c}{ }^{\prime}$ are used in transformations which resemble absence of zero sequence component and it is given in Equation (6). Thus in three phase four wire it was modified as $v_{\alpha}{ }^{\prime}, v_{\beta}{ }^{\prime}$ and it is given in Equation (7).

$$
\begin{gathered}
{\left[\begin{array}{c}
v_{a}^{\prime} \\
v_{b}^{\prime} \\
v_{c}^{\prime}
\end{array}\right]=\sqrt{\frac{2}{3}}\left[\begin{array}{cc}
1 & 0 \\
-\frac{1}{2} & \frac{\sqrt{3}}{2} \\
-\frac{1}{2} & -\frac{\sqrt{3}}{2}
\end{array}\right]\left[\begin{array}{c}
v_{\alpha}^{\prime} \\
v_{\beta}^{\prime}
\end{array}\right]} \\
{\left[\begin{array}{c}
v_{\alpha}^{\prime} \\
v_{\beta}^{\prime}
\end{array}\right]=\frac{1}{i \alpha^{\prime 2}+i \beta^{\prime 2}}\left[\begin{array}{cc}
i \alpha^{\prime} & -i \beta^{\prime} \\
i \beta^{\prime} & i \alpha^{\prime}
\end{array}\right]\left[\begin{array}{l}
\overline{p^{\prime}} \\
\overline{q^{\prime}}
\end{array}\right]}
\end{gathered}
$$

\section{DC voltage regulator $(p-q)$ :}

The dc capacitor voltages $V_{d c 1}$ and $V_{d c 2}$ may be controlled by a dc voltage regulator. A low-pass filter with cut-off frequency $20 \mathrm{~Hz}$ is used to render it insensitive to the fundamental frequency $(50 \mathrm{~Hz})$ voltage variations.

The filtered voltage difference $\Delta V=V_{d c 2}-V_{d c 1}$ produces voltage regulation $\varepsilon$ according to the following limit function generator: 


$$
\begin{array}{ccc}
\varepsilon=-1 ; & \Delta V<-0.05 V_{r e f} \\
\varepsilon=\frac{\Delta V}{-0.05 V_{r e f}} ; & -0.05 V_{r e f} \leq \Delta V \leq 0.05 V_{r e f} \\
\varepsilon=1 ; & \Delta V>0.05 V_{r e f}
\end{array}
$$

where $V_{\text {ref }}$ is a pre-defined dc voltage reference and 0.05 $V_{\text {ref }}$ was arbitrarily chosen as an acceptable tolerance margin for voltage variations.

If $\left(V_{d c 1}+V_{d c 2}\right)<V_{r e f}$, the PWM inverter should absorb energy from the ac network to charge the dc capacitor. The inverse occur if $\left(V_{d c 1}+V_{d c 2}\right)>V_{\text {ref }}$.

The signal $\overline{P_{\text {loss }}}$ generated in the dc voltage regulator is useful for correcting voltage variations due to compensation errors that may occur during the transient response of shunt active filter.

\subsection{Instantaneous Active and Reactive Current $\operatorname{Method}\left(i_{d}-i_{q}\right)$}

In this method reference currents are obtained through instantaneous active and reactive currents $i_{d}$ and $i_{q}$ of the non linear load. Calculations follows Similar to the instantaneous power theory, however $d q$ load currents can be obtained from Equation (8). Two stage transformations give away relation between the stationary and rotating reference frame with active and reactive current method [9-11]. Figure 4 shows voltage and current vectors in stationary and rotating reference frames. The transformation angle ' $\theta$ ' is sensible to all voltage harmonics and unbalanced voltages; as a result $d \theta / d t$ may not be constant. Arithmetical relations are given in Equations (8) and (9); finally reference currents can be obtained from Equation (10).

$$
\left[\begin{array}{c}
i_{d} \\
i_{q}
\end{array}\right]=\frac{1}{\sqrt{v_{\alpha}^{2}+v_{\beta}^{2}}}\left[\begin{array}{cc}
v_{\alpha} & v_{\beta} \\
-v_{\beta} & v_{\alpha}
\end{array}\right]\left[\begin{array}{l}
i_{\alpha} \\
i_{\beta}
\end{array}\right]
$$

where $i_{\alpha}, i_{\beta}$ are the instantaneous $\alpha-\beta$ axis current references

$$
\begin{gathered}
{\left[\begin{array}{l}
i_{d} \\
i_{q}
\end{array}\right]=\left[\begin{array}{cc}
\cos \theta & \sin \theta \\
-\sin \theta & \cos \theta
\end{array}\right]\left[\begin{array}{l}
i_{\alpha} \\
i_{\beta}
\end{array}\right]} \\
{\left[\begin{array}{c}
i c_{\alpha} \\
i c_{\beta}
\end{array}\right]=\frac{1}{\sqrt{v_{\alpha}^{2}+v_{\beta}^{2}}}\left[\begin{array}{cc}
v_{\alpha} & -v_{\beta} \\
v_{\beta} & v_{\alpha}
\end{array}\right]\left[\begin{array}{l}
i c_{d} \\
i c_{q}
\end{array}\right]}
\end{gathered}
$$

where $i_{c d}, i_{c q}$ are compensation currents.

One of the advantages of this method is that angle $\theta$ is calculated directly from main voltages and thus makes this method frequency independent by avoiding the PLL in the control circuit. Consequently synchronizing problems with unbalanced and distorted conditions of main voltages are also evaded. Thus $i_{d}-i_{q}$ achieves large fre- quency operating limit essentially by the cut-off frequency of voltage source inverter (VSI) [12]. Figures 3 and 5 show the control diagram for shunt active filter and harmonic injection circuit. On owing load currents $i_{d}$ and $i_{q}$ are obtained from park transformation then they are allowed to pass through the high pass filter to eliminate dc components in the nonlinear load currents. Filters used in the circuit are Butterworth type and to reduce the influence of high pass filter an alternative high pass filter (AHPF) can be used in the circuit. It can be obtained through the low pass filter (LPF) of same order and cut-off frequency simply difference between the input signal and the filtered one, which is clearly shown in

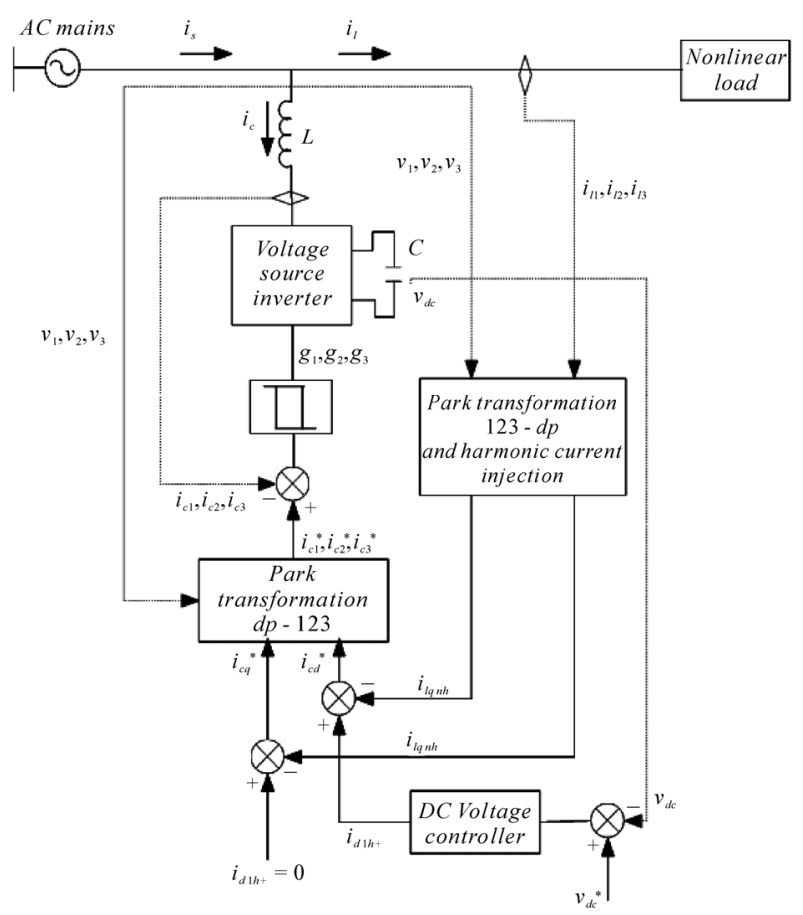

Figure 3. Active powers filter control circuit.

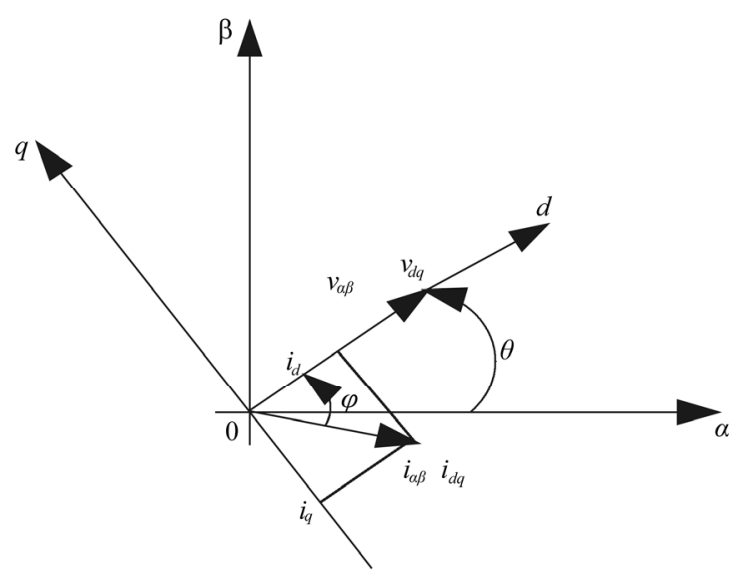

Figure 4. Instantaneous voltage and current vectors. 


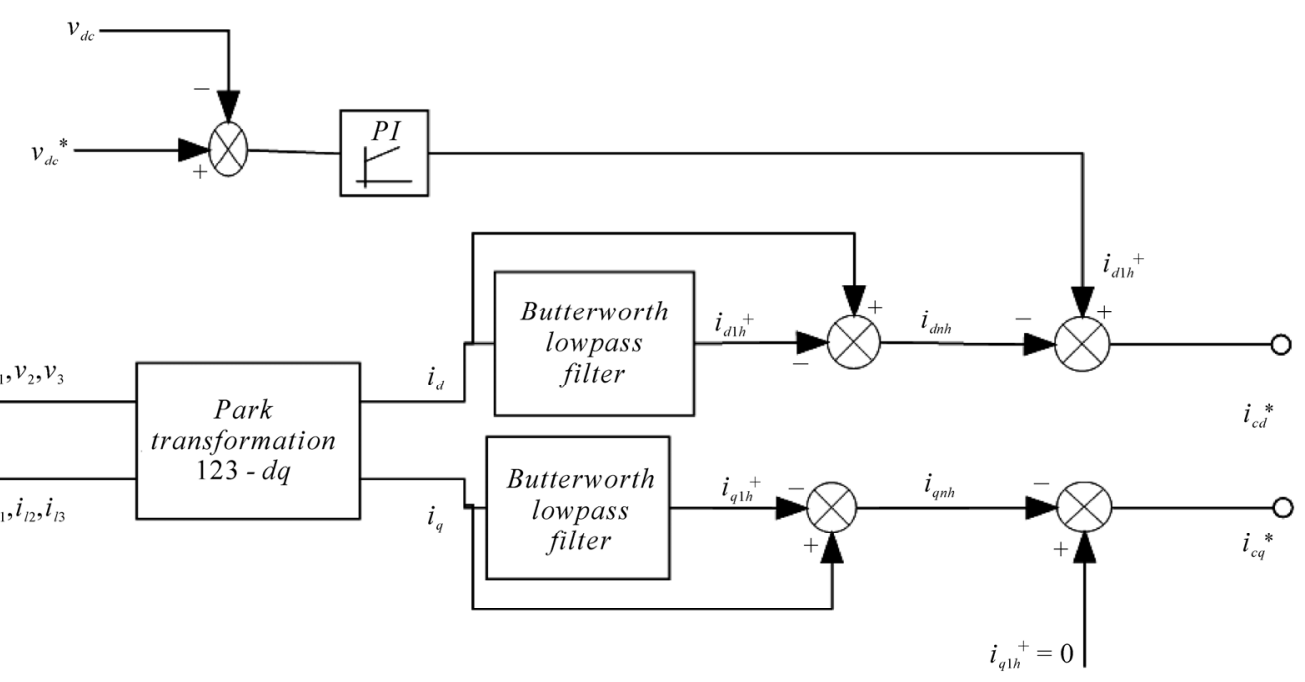

Figure 5. Park transformation and harmonic current injection circuit.

Figure 5. Butterworth filters used in harmonic injecting circuit have cut-off frequency equal to one half of the main frequency $\left(f_{c}=f / 2\right)$, with this a small phase shift in harmonics and sufficiently high transient response can be obtained.

\section{Voltage regulator $\left(I_{d}-I_{q}\right)$}

The function of voltage regulator on dc side is performed by proportional - integral (PI) controller, inputs to the PI controller are, change in dc link voltage $\left(V_{d c}\right)$ and reference voltage $\left(V_{d c}{ }^{*}\right)$, on regulation of first harmonic active current of positive sequence $i_{d l h}{ }^{+}$it is possible to control the active power flow in the VSI and thus the capacitor voltage $V_{d c}$.

In similar fashion reactive power flow is controlled by first harmonic reactive current of positive sequence $i_{q l h}{ }^{+}$. On the contrary the primary end of the active power filters is just the exclusion of the harmonics caused by nonlinear loads hence the current $i_{q I h}{ }^{+}$is always set to zero.

\section{Construction of Fuzzy Logic Controller}

The concept of Fuzzy Logic (FL) was proposed by Professor Lotfi Zadeh in 1965, at first as a way of processing data by allowing partial set membership rather than crisp membership. Soon after, it was proven to be an excellent choice for many control system applications since it mimics human control logic.

Figure 6 shows the internal structure of the control circuit. The control scheme consists of Fuzzy controller, limiter, and three phase sine wave generator for reference current generation and generation of switching signals [13]. The peak value of reference currents is estimated by regulating the DC link voltage. The actual capacitor voltage is compared with a set reference value. The error signal is then processed through a Fuzzy controller, which contributes to zero steady error in tracking the reference current signal.

A fuzzy controller converts a linguistic control strategy into an automatic control strategy, and fuzzy rules are constructed by expert experience or knowledge database. Firstly, input voltage $V_{d c}$ and the input reference voltage $\mathrm{V}_{\mathrm{dc} \text {-ref }}$ have been placed of the angular velocity to be the input variables of the fuzzy logic controller [14]. Then the output variable of the fuzzy logic controller is presented by the control Current $I_{\max }$. To convert these numerical variables into linguistic variables, the following seven fuzzy levels or sets are chosen as: NB (negative big), NM (negative medium), NS (negative small), ZE (zero), PS (positive small), PM (positive medium), and $\mathrm{PB}$ (positive big) as shown in Figure 7.

The fuzzy controller is characterized as follows:

1) Seven fuzzy sets for each input and output.

2) Fuzzification using continuous universe of discourse.

3) Implication using Mamdani's 'min' operator.

4) De-fuzzification using the 'centroid' method.

Rule Base:

The elements of this rule base table are determined based on the theory that in the transient state, large errors need coarse control, which requires coarse input/output variables; in the steady state, small errors need fine control, which requires fine input/output variables. Based on this the elements of the rule table are obtained as shown in Table 1, with ' $\mathrm{V}_{\mathrm{dc}}$ ' and ' $\mathrm{V}_{\mathrm{dc}-\mathrm{ref}}$ ' as inputs.

Fuzzification: The process of converting a numerical variable (real number) convert to a linguistic variable (fuzzy number) is called fuzzification.

De-fuzzification: The rules of FLC generate required output in a linguistic variable (Fuzzy Number), accord- 


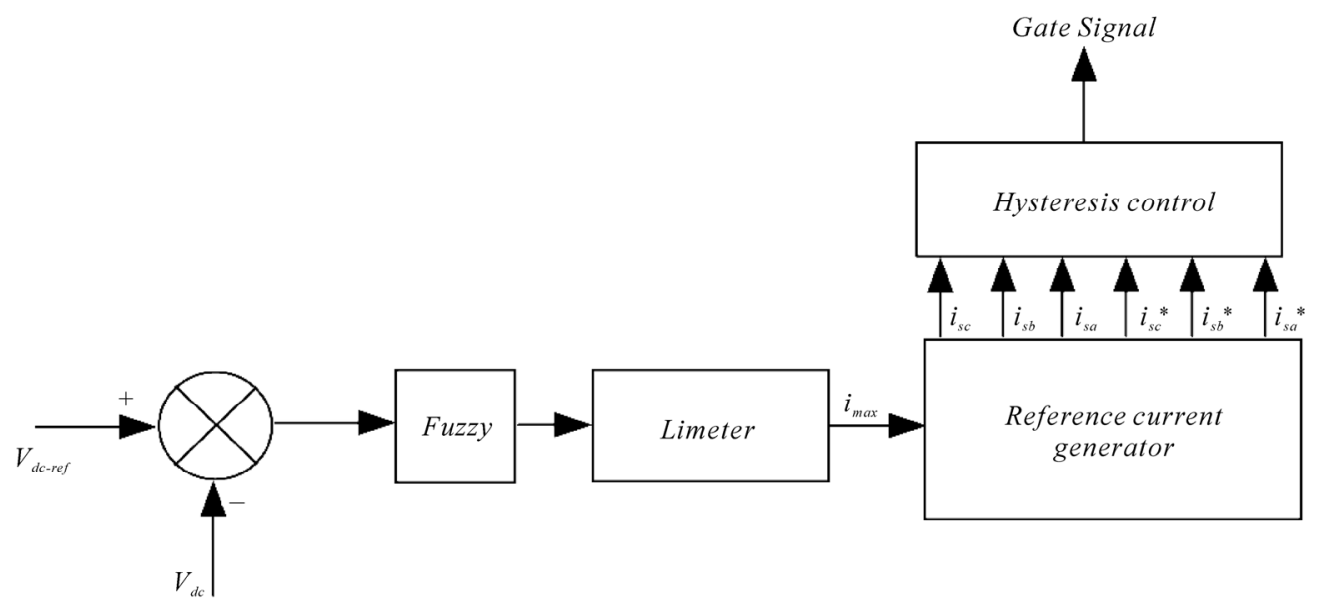

Figure 6. Conventional fuzzy controller.

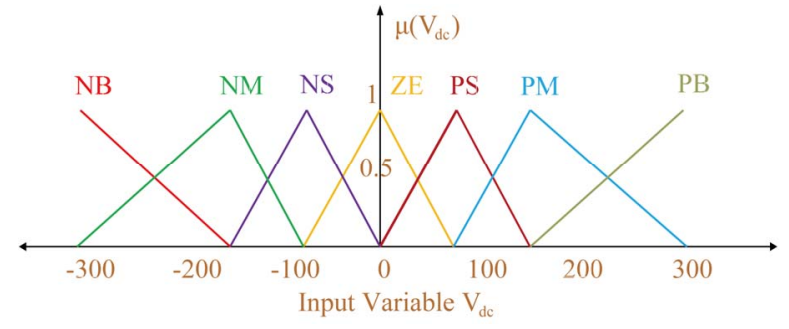

(a)

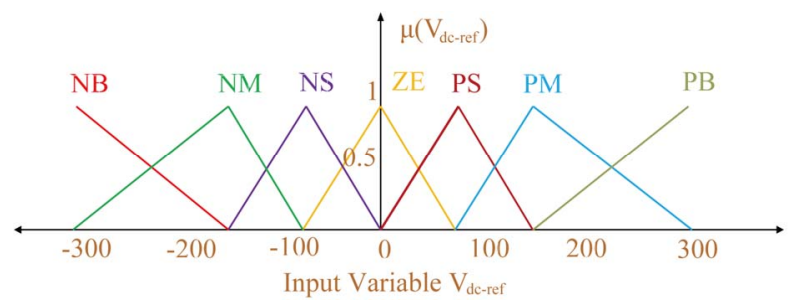

(b)

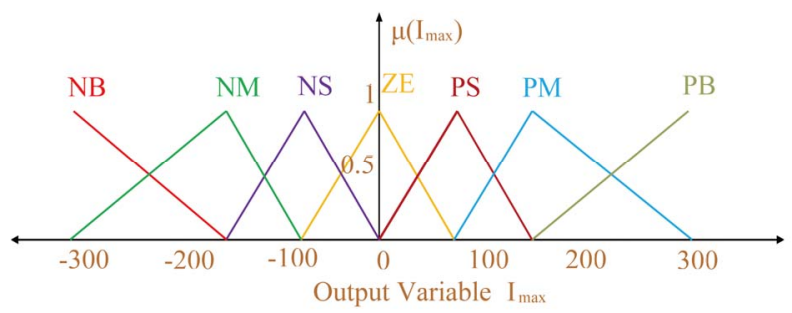

(c)

Figure 7. (a) Input $V_{d c}$ normalized membership function; (b) input $V_{\text {dc-ref }}$ normalized membership function; (c) output $I_{\text {max }}$ normalized membership function.

ing to real world requirements, linguistic variables have to be transformed to crisp output (Real number).

Database: The Database stores the definition of the membership Function required by fuzzifier and defuzzifier.
Table 1. Rule base.

\begin{tabular}{cccccccc}
\hline $\begin{array}{c}V_{\text {de-ref }} \\
V_{\text {de }}\end{array}$ & NB & NM & NS & $Z$ & PS & PM & PB \\
\hline NB & NB & NB & NB & NB & NM & NS & $Z$ \\
NM & NB & NB & NB & NM & NS & $Z$ & PS \\
NS & NB & NB & NM & NS & Z & PS & PM \\
$Z$ & NB & NM & NS & Z & PS & PM & PB \\
PS & NM & NS & Z & PS & PM & PB & PB \\
PM & NS & Z & PS & PM & PB & PB & PB \\
PB & $Z$ & PS & PM & PB & PB & PB & PB \\
\hline & & & & & & &
\end{tabular}

\section{System Performance}

In this section 3 phase 4 wire shunt active power filter responses are presented in transient and steady state conditions. In the present simulation AHPF (alternative high pass filter) were used in Butterworth filter with cut-off frequency $f_{c}=f / 2$. Simulation shown here are for different voltage conditions like sinusoidal, non-sinusoidal, unbalanced, and with different main frequencies. Simulation is carried out for both instantaneous power theory $(p-q)$ and instantaneous active and reactive current theory $\left(i_{d^{-}} i_{q}\right)$ with Fuzzy controller.

Figures 8-10 illustrate the performance of shunt active power filter under different main voltages, as load is highly inductive, current draw by load is integrated with rich harmonics.

Figure 8 illustrates the performance of Shunt active power filter under balanced sinusoidal voltage condition. THD for $p-q$ method with Fuzzy controller is about $1.45 \%$ and THD for $i_{d}-i_{q}$ method with Fuzzy Controller is $1.14 \%$

Figure 9 illustrates the performance of Shunt active 


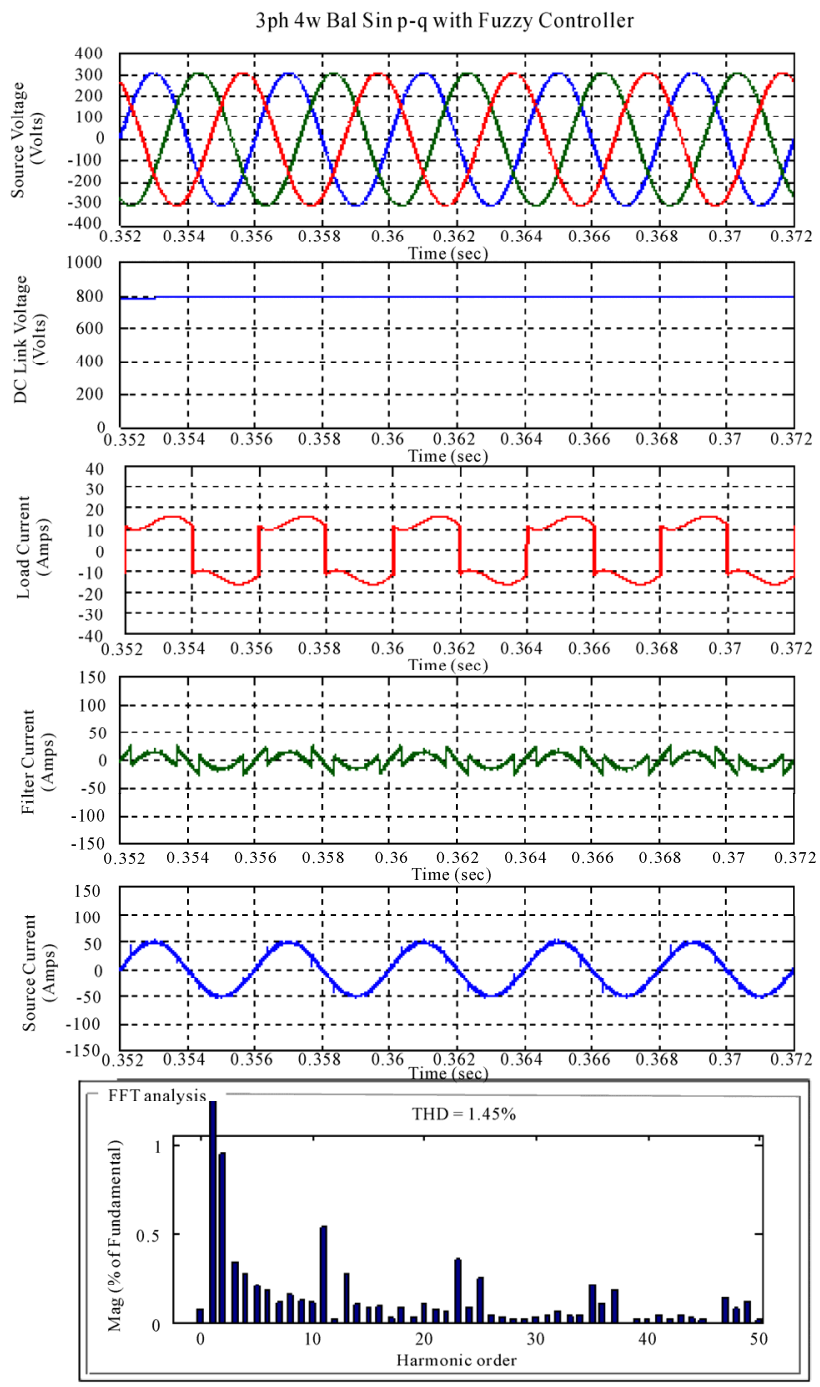

(a)

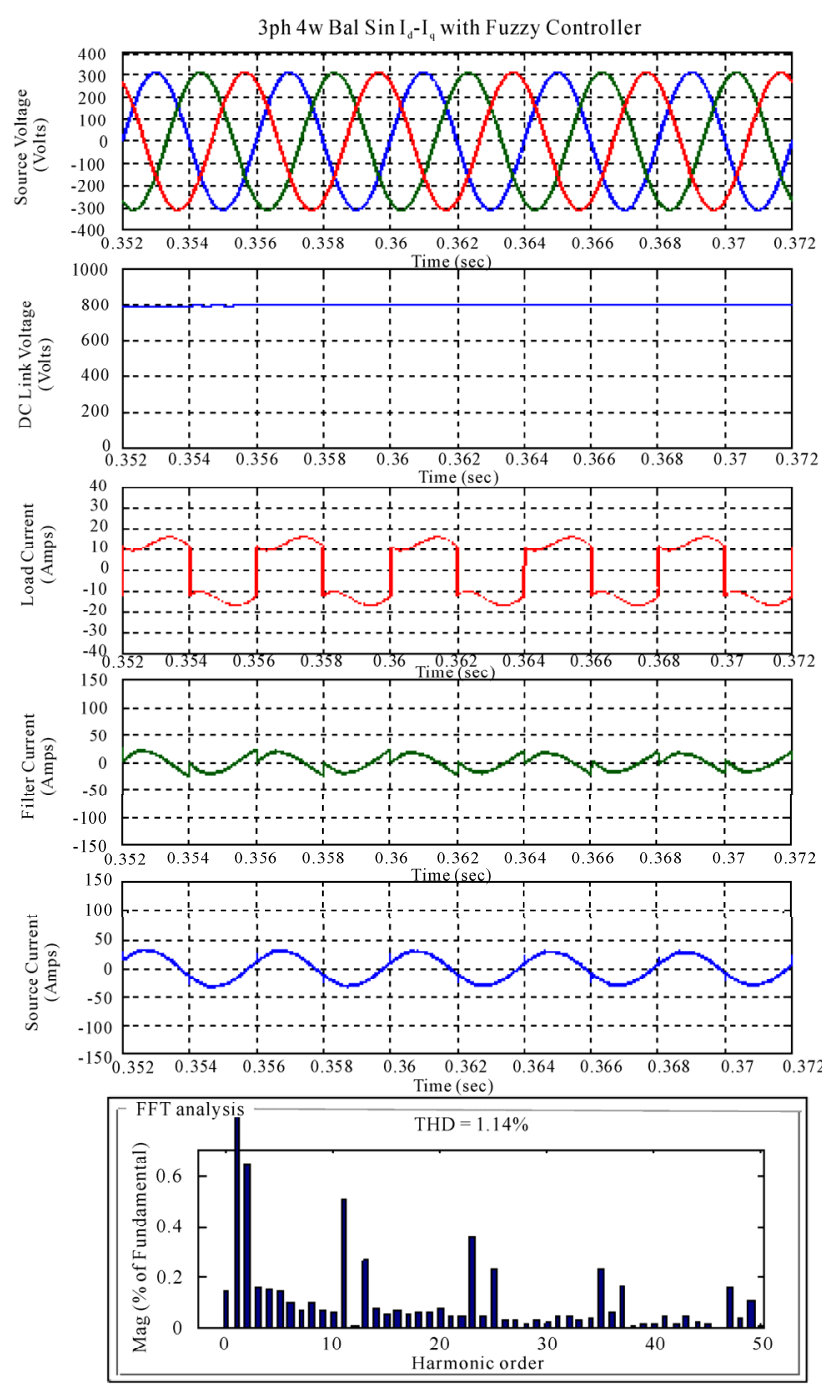

(b)

Figure 8. 3ph 4wire Shunt ative filter response with fuzzy controller under balanced sinusoidal (a) using p-q control strategy (b) using $\mathbf{I}_{\mathbf{d}}-\mathbf{I}_{\mathbf{q}}$ control strategy.

power filter under un-balanced sinusoidal voltage condition. THD for $p-q$ method with Fuzzy controller is 3.73\% and THD for $i_{d}-i_{q}$ method with Fuzzy Controller is $2.27 \%$.

Figure 10 illustrates the performance of Shunt active power filter under balanced non-sinusoidal voltage condition. THD for $p-q$ method with Fuzzy controller is $5.11 \%$ and THD for $i_{d}-i_{q}$ method with Fuzzy Controller is $4.09 \%$.

On observing $p-q$ control strategy fails to deliver reference currents properly under unbalance and non-sinusoidal conditions. So harmonic content seems to very high in $p-q$ control strategy under these conditions. On owing $i_{d}-i_{q}$ control strategy delivers exact reference currents under any voltage conditions. As a result with the id-iq control strategy one can attain perfect compensation.

Fuzzy controller is finest controller in all the controllers, but it too has some drawbacks like redundancy and iteration problems. So one has to choose the membership function on the bases system complexity Extensive simulation is carried out to validate both $\mathrm{p}-\mathrm{q}$ and $\mathrm{I}_{\mathrm{d}}-\mathrm{I}_{\mathrm{q}}$ methods with fuzzy controller; on over all with combination of $I_{d}-I_{q}$ strategy and fuzzy controller, there is possibility of building novel shunt active filter for 3-phase 4-wire system.

\section{Numerical simulations:}

Above simulation is carried out with only AHPF (alternative high pass filter) of $2^{\text {nd }}$ order with cut-off frequency $f_{c}=f_{c} / 2$, it is also assumed that currents are in- 


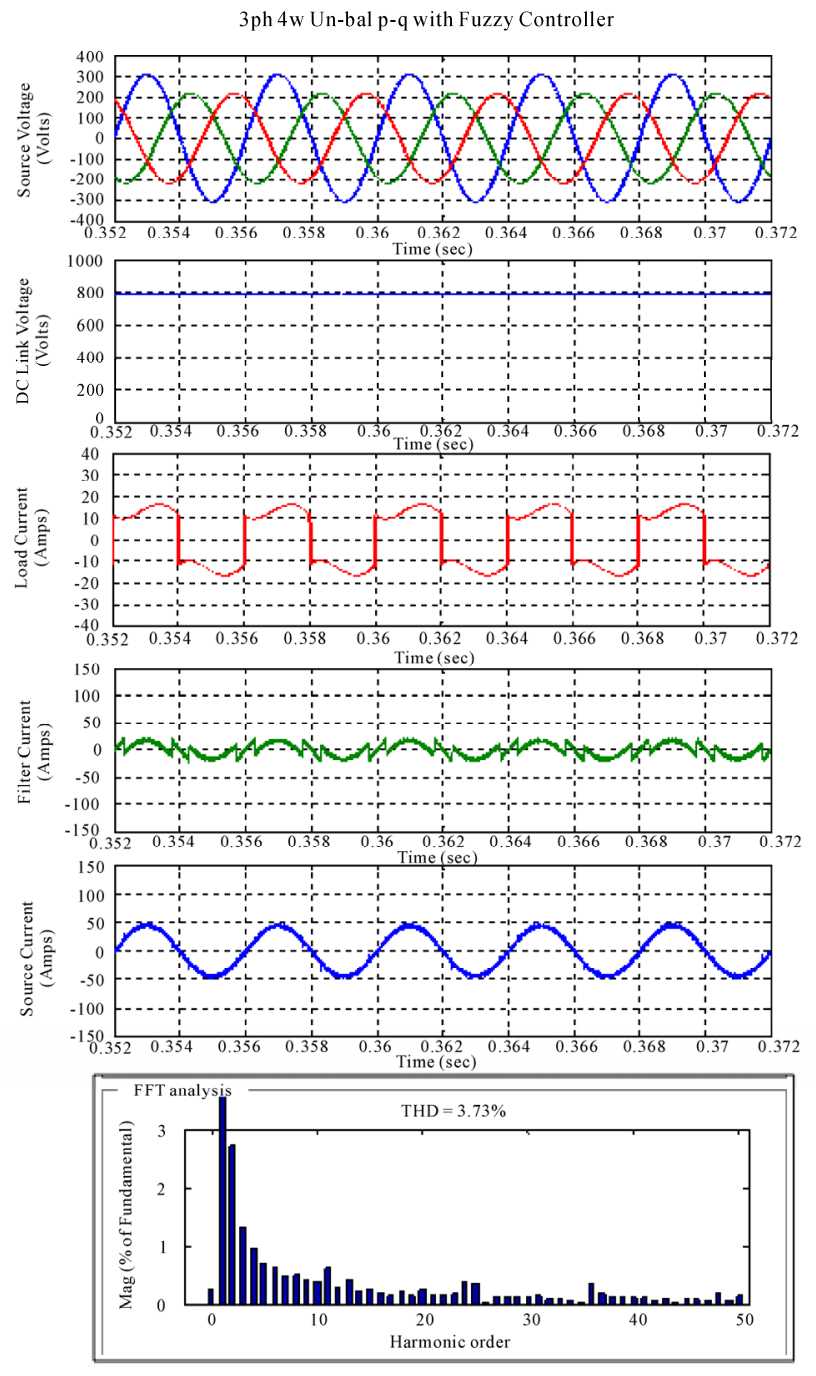

(a)

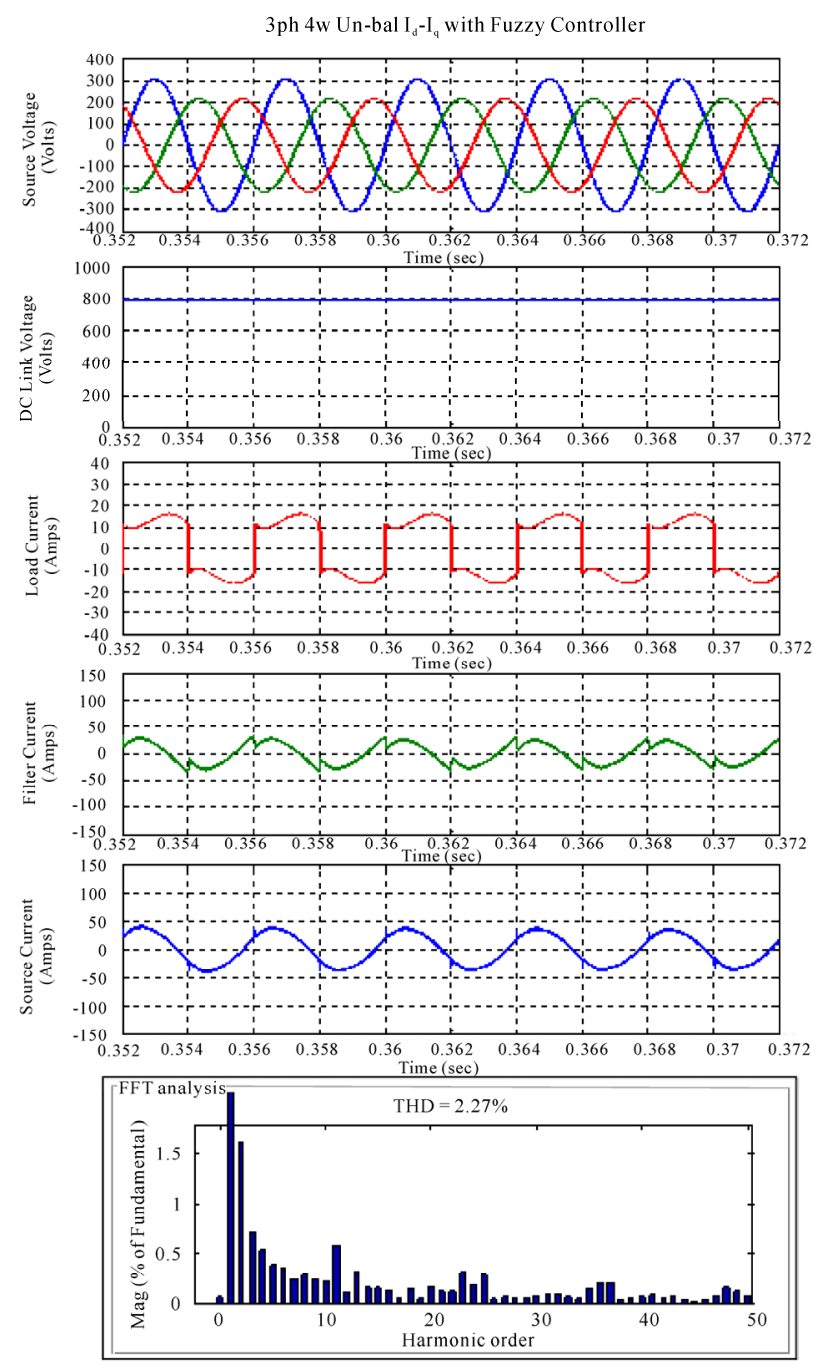

(b)

Figure 9. 3ph 4wire Shunt ative filter response with fuzzy controller under un-balanced sinusoidal (a) using p-q control strategy (b) using $\mathbf{I}_{\mathbf{d}}-\mathbf{I}_{\mathbf{q}}$ control strategy.

dependent of main voltages and there is no ripple on the rectifier dc current. Active power filter performance is analysed under several main voltage conditions. In addition simulation is also extended to different kinds of filters like HPF (high pass filter) with $2^{\text {nd }}$ order, AHPF with $4^{\text {th }}$ order and HPF with $4^{\text {th }}$ order. In all those, Alternative high pass filter shows good performance and it is easy to obtain with LPF (low pass filter) of same order and cut-off frequency, simply by difference between the input and filter signal which is shown in Figure 4. Graphs shown in Figure 11 and Figure 12 summarize the total performance of the shunt active filter with different filters. Results presented confirm superior performance of $\mathrm{I}_{\mathrm{d}}-\mathrm{I}_{\mathrm{q}}$ method with Fuzzy controller. But performance of shunt active filters with both methods ( $p-q$ and $\left.I_{d}-I_{q}\right)$ un- der sinusoidal conditions performance same. Generally speaking in all the filters, HPF gives best filtering action under any voltage conditions.

\section{Conclusion}

In the present paper two control strategies are developed and verified with three phase four wire system. Though the two strategies are capable to compensate current harmonics in the 3 phase 4 -wire system, but it is observed that instantaneous active and reactive current $i_{d}-i_{q}$ method with fuzzy controller lead always better result under un-balanced and non-sinusoidal voltage conditions over the instantaneous active and reactive power $p-q$ method. On contrast $p-q$ theory needs additional PLL 


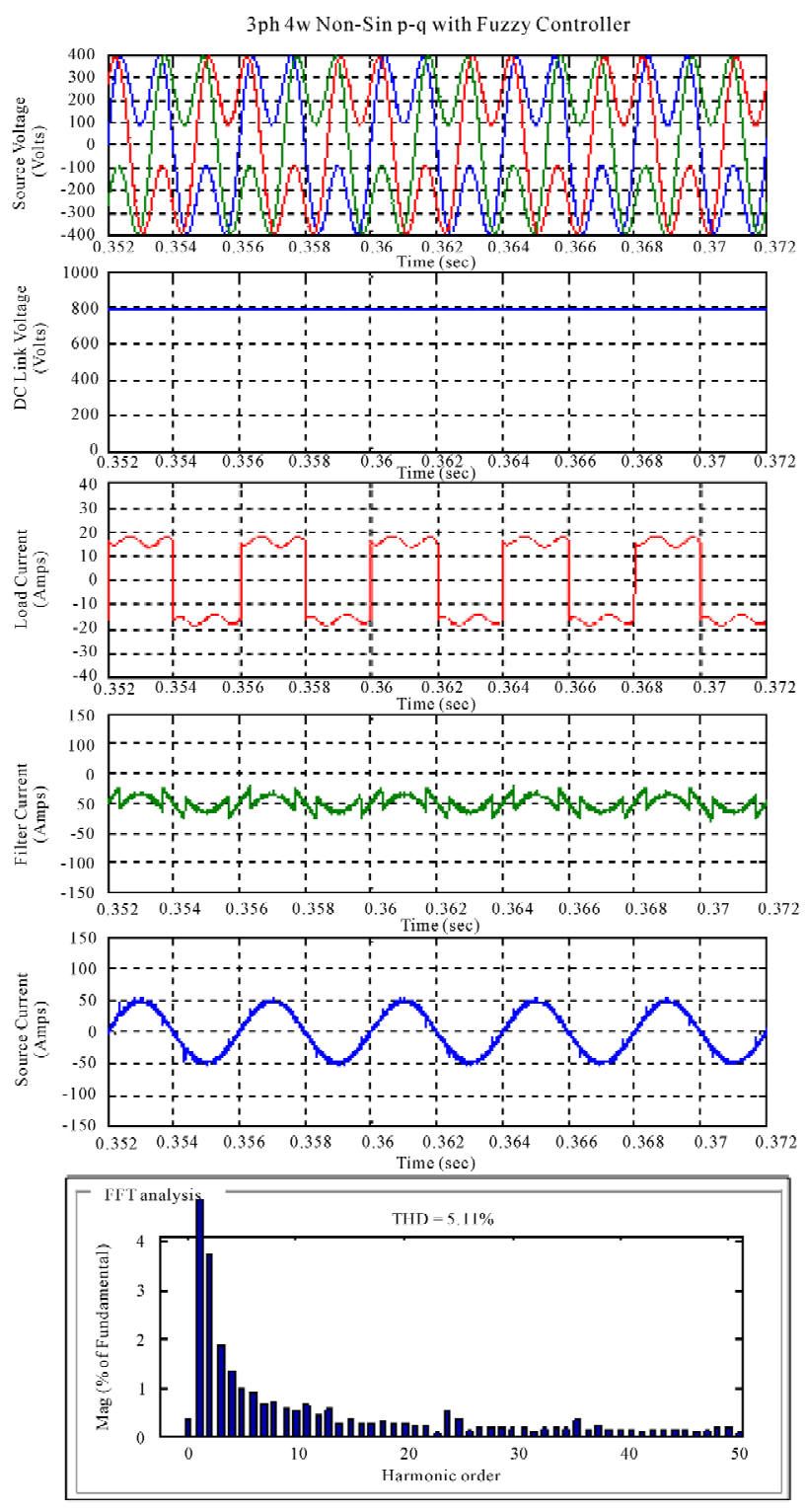

(a)
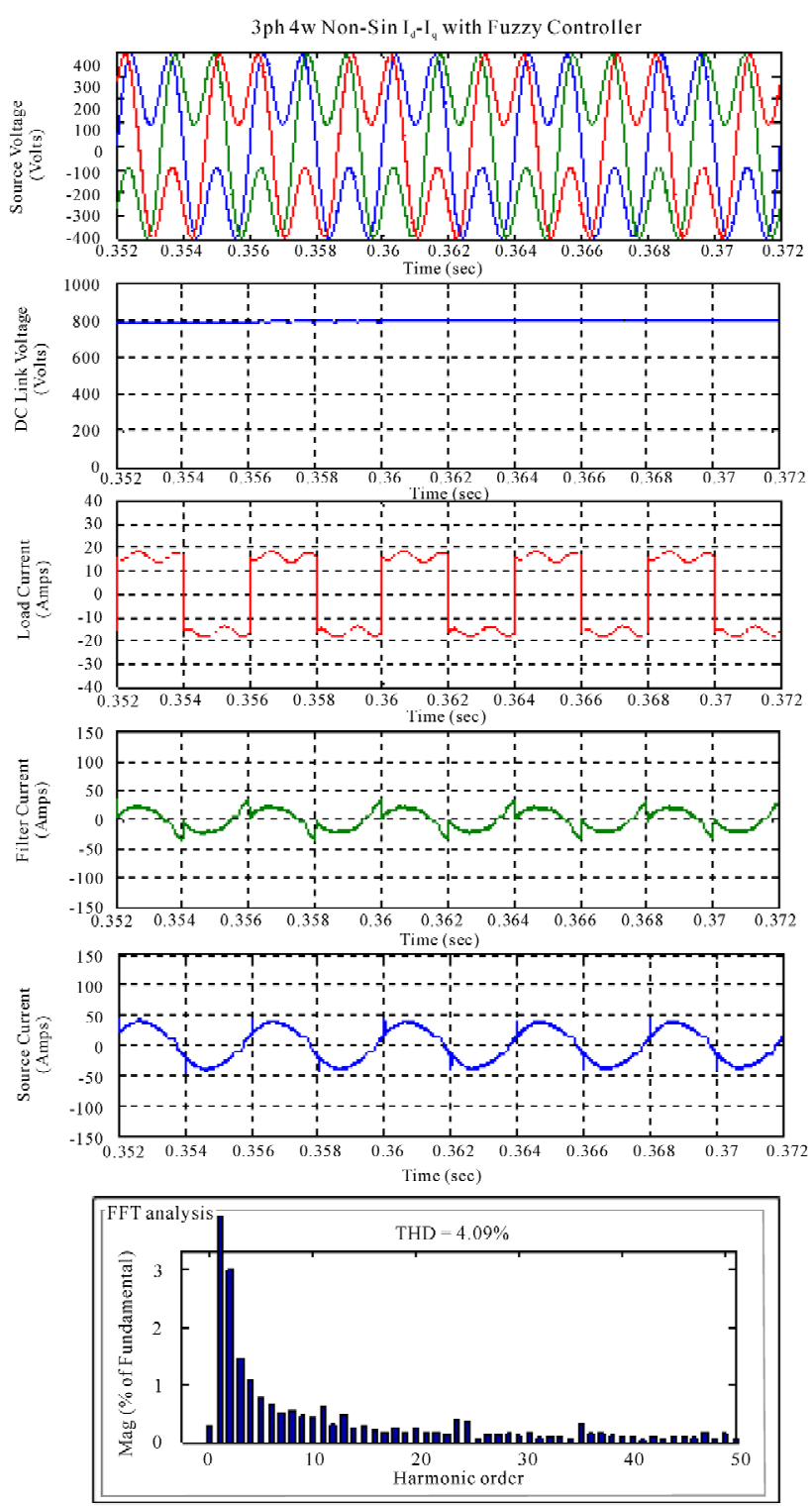

(b)

Figure 10. 3ph 4wire shunt ative filter response with fuzzy controller under balanced non-sinusoidal (a) using p-q control strategy (b) using $I_{d}-I_{q}$ control strategy.

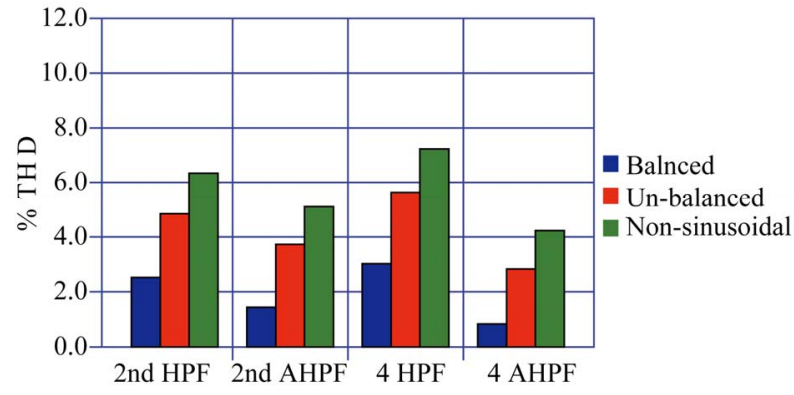

Figure 11. THD for p-q method with fuzzy controller.

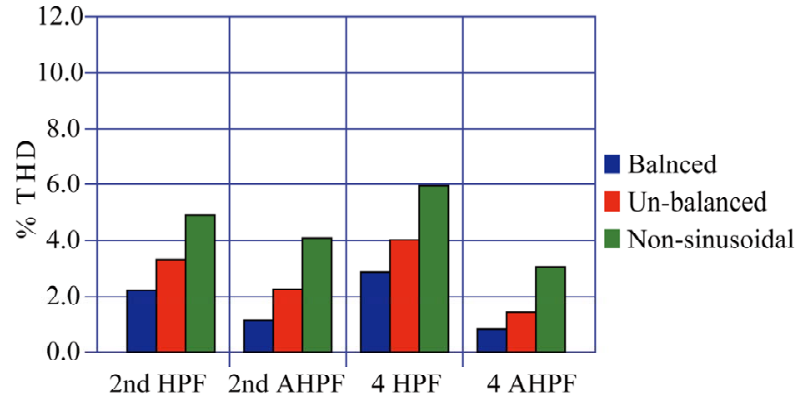

Figure 12. THD for $i_{d}-i_{q}$ method with fuzzy controller. 


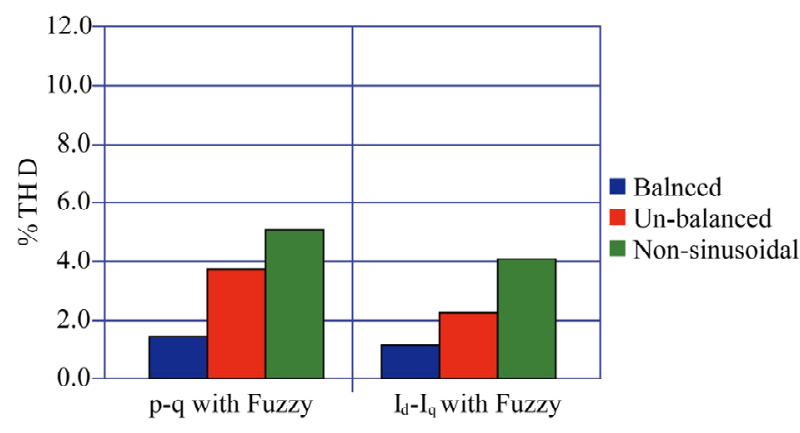

Figure 13. THD for $p-q$ and $i_{d}-i_{q}$ methods with fuzzy controller.

circuit for synchronization so $p-q$ method is frequency variant, where as in $i_{d}-i_{q}$ method angle

' $\theta$ ' is calculated directly from main voltages and thus enables the method to be frequency independent. Thus large numbers of synchronization problems with unbalanced and non-sinusoidal voltages are also avoided. Addition to that DC voltage regulation system valid to be a stable and steady-state error free system was obtained. Over all, performance of $i_{d}-i_{q}$ theory with fuzzy controller is quite good over $p-q$ theory with fuzzy controller.

\section{References}

[1] H. Akagi, "New Trends in Active Filters for Power Conditioning," IEEE Transactions on Industry Applications, Vol. 32, No. 6, November-December 1996, pp. 13121322. doi.:10.1109/28.556633

[2] Z. Peng, G. W. Ott and D. J. Adams, "Harmonic and Reactive Power Compensation Based on the Generalized Instantaneous Reactive Power Theory for Three-Phase Four-Wire Systems," IEEE Transactions on Power Electronics, Vol. 13, No. 5, November 1998, pp. 1174-1181. doi: $10.1109 / 63.728344$

[3] S. K. Jain, P. Agrawal and H. O. Gupta, "Fuzzy Logic Controlled Shunt Active Power Filter for Power Quality Improvement," IEE Proceedings of Electric Power Application, Vol. 149, No. 5, September 2002, pp. 317-328. doi:10.1049/ip-epa:20020511

[4] L. Gyugyi and E. C. Strycula, "Active AC Power Filters," IEEE IIAS Annual Meeting, 1976, p. 529.

[5] M. I. M. Montero, E. R. Cadaval and F. B. González, "Comparison of Control Strategies for Shunt Active
Power Filters in Three-Phase Four-Wire Systems," IEEE Transactions on Power Electronics, Vol. 22, No. 1, January 2007, pp. 229-236. doi:10.1109/TPEL.2006.886616

[6] H. Akagi, E. H. Watanabe and M. Aredes, "Instantaneous Power Theory and Applications to Power Conditioning," IEEE Press/Wiley-Inter-Science, New Jersey, 2007.

[7] O. Vodyakho and C. C. Mi, "Three-Level Inverter-Based Shunt Active Power Filter in Three-Phase Three-Wire and Four-Wire Systems," IEEE Transactions on Power Electronics, Vol. 24, No. 5, May 2009, pp. 1350-1363. doi:10.1109/TPEL.2009.2016663

[8] M. Aredes, J. Hafner and K. Heumann,"Three-Phase Four-Wire Shunt Active Filter Control Strategies," IEEE Transactions on Power Electronics, Vol. 12, No. 2, March 1997, pp. 311-318. doi:10.1109/63.558748

[9] P. Rodriguez, J. I. Candela, A. Luna, L. Asiminoaei, R. Teodorescu and F. Blaabjerg, "Current Harmonics Cancellation in Three-Phase Four-Wire Systems by Using a Four-Branch Star Filtering Topology," IEEE Transactions on Power Electronics, Vol. 24, No. 8, August 2009, pp. 1939-1950.

[10] P. Salmeron and R. S. Herrera, "Distorted and Unbalanced Systems Compensation within Instantaneous Reactive Power Framework," IEEE Transactions on Power Delivery, Vol. 21, No. 3, July 2006, pp. 1655-1662. doi: 10.1109/TPWRD.2006.874115

[11] N. G. Jayanti, M. Basu, I. Axente, K. Gaughan and. F. Conlon, "Development of Laboratory Prototype of a 12 kVA Digital Shunt Active Filter," Proceedings of 34th IEEE Industrial Electronics Conference (IECON), Florida, 10th-13th November 2008, pp. 3129-3134.

[12] V. Soares, P. Verdelho and G. Marques, "Active Power Filter Control Circuit Based on the Instantaneous Active and Reactive Current $i_{d}-i_{q}$ Method," IEEE Power Electronics Specialists Conference, Vol. 2, 1997, pp. 10961101.

[13] P. Kirawanich and R. M. O'Connell, "Fuzzy Logic Control of an Active Power Line Conditioner," IEEE Transactions on Power Electronics, Vol. 19, No. 6, November 2004, pp. 1574-1585. doi:10.1109/TPEL.2004.836631

[14] C. S. Perumalla, P. C. Panda and S. Mishra, "Fuzzy Controlled Harmonic Suppressor and Reactive Volt Ampere Compensator for Enhancing Power Quality," 2009 World Congress on Nature \& Biologically Inspired Computing (NaBIC 2009), Coimbatore, December 2009, pp. 49-54 doi:10.1109/ NABIC.2009.5393599 